EESTI NSV TEADUSTE AKADEEMIA TOIMETISED. 19. KOIDE

KEEMIA * GEOLOOGIA. 1970, Nr. 4

ИЗВЕСТИЯ АКАДЕМИИ НАУК ЭСТОНСКОИ ССР. ТОМ 19

ХИМИЯ * ГЕОЛОГИЯ. 1970, № 4

ВЕРА ПУНГА, А. ФОМИНА, З. ДЕГТЕРЕВА, И. ПОПУШОН

\title{
ИССЛЕДОВАНИЕ БИОЛОГИЧЕСКОГО ДЕЙСТВИЯ СРВ НА РАЗВИТИЕ РАСТЕНИИ
}

В Институте химии АН ЭССР разработан способ получения насыщенных дикарбоновых кислот из керогена сланца-кукерсита. В этом процессе в качестве сопутствующего продукта образуются сланцевые полифункциональные кислоты. Проведенными исследованиями установлено, что соли этих кислот (калиевые, натриевые, аммониевые, кальциевые, бариевые и др.) обладают стимулирующим действием на рост растений [']. Однако более подробного биологического исследования их действия как на разные виды культурных растений, так и на отдельные их органы еще не проводилось.

Настоящее сообщение содержит материалы исследования действия водных растворов калиевых и кальциевых солей сланцевых полифункциональных кислот на рост проростков и развитие растений табака сорта 'Трапезонд 1867' и гибрида 'Иммунного' с 'Маловатой' в тепличных условиях и в открытом грунте.

Обработка растворами сланцевого ростового вещества (СРВ) в условиях теплицы проводилась следующим образом: во-первых, замачивание семян в растворах СРВ (0,1\%-ной концентрации), а затем трехкратное опрыскивание рассады с промежутками в 7-10 дней.

Активность действия СРВ выявлялась путем измерения длины проростков, а также ширины и длины наибольшего листа рассады.

Для полевых опытов применялся способ замачивания корневой системы рассады перед высадкой в грунт и опрыскивание растений в различные периоды развития на обычном агрофоне и при дополнительном минеральном питании.

Биологические испытания СРВ проводились на базе Института физнологии и биохимии растений Академии наук Молдавской ССР (г. Кишенев) под руководством чл.-корр. АН МССР доктора биологических наук И. Попушой в 1969 г.

\section{Изучение действия СРВ в тепличных условиях}

В проведенном исследовании было испытано шесть проб СРВ, отличающихся, во-первых, по характеру катионов калия и кальция (калиевая соль хорошо растворима в воде, кальциевая - не полностью) и, во-вторых, по полифункциональным кислотам. Одни из них готовились из концентрата керогена производства 1965 г. (ПФК-211), другие 1968 г. (ПФК-212) и 1969 г. (ПФК-213). Это сделано для выявления биологическими методами влияния старения керогена на качество ПФК.

Обозначения СРВ-1 (ҚП-211, 212, 213) расшифровываются как калиевые соли полифункцнональных кислот из опытов $211,212,213$, 
а СРВ-4 (СаП-211, 212, 213) - как кальциевые соли полифункциональных кислот из опытов 211, 212 и 213.

1. Влияние СРВ на всхожесть семян. Семена табака сорта 'Трапезонд 1867' замачивались в течение 17 є в чашках Петри в 0,1\%-ных растворах СРВ-1 и СРВ-4. Замачивание проводилось при комнатной температуре. После замачивания семена высушивались на воздухе и высевались в чашки Петри с влажной ватной прослойкой. Проращивание проводилось в термостате при температуре $27^{\circ} \mathrm{C}$. Через два дня все семена наклюнулись. Между контрольными и опытными проростками существенной разницы обнаружено не было.

Десятидневные проростки осторожно вырывались по десяти штук из каждой чашки и измерялась длина. Средние данные десяти измерений после статистической обработки методом дисперсионного анализа, описанным Б. Доспеховым [ $\left.{ }^{2}\right]$, представлены в табл. 1. Данные измерений показали, что опытные проростки длиннее контрольных в основном за счет корешков.

Таблица ।

Изменение морфологических показателей у рассады табака под воздействием СРВ

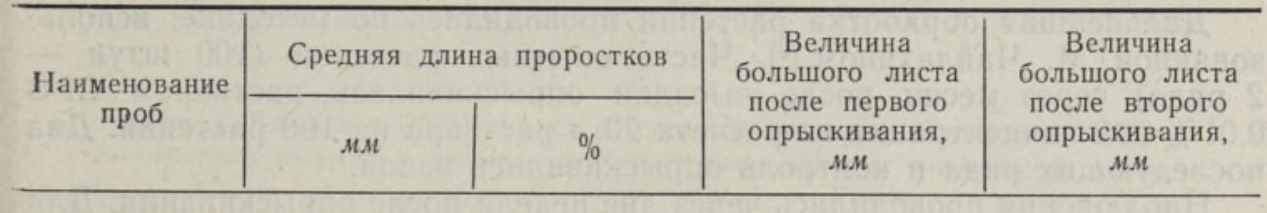

\section{Контроль}

КП-211

СaП-211

КП-212

CaП-212

КП-213

СаП-213

$\begin{array}{ll}13,6 & 100 \\ 15,0 & 110 \\ 15,7 & 115 \\ 15,0 & 110 \\ 15,1 & 111 \\ 15,3 & 113 \\ 15,5 & 114\end{array}$

$16,3 \times 13,6$

$19,9 \times 15,6$

$23,8 \times 18,6$

$22,8 \times 18,8$

$21,3 \times 16,8$

$21,1 \times 16,3$

$21,0 \times 16,6$
$24,5 \times 19,7$

$38,8 \times 30,2$

$45,0 \times 34,0$

$44,3 \times 33,2$

$40,8 \times 30,6$

$39,0 \times 30,2$

$40,0 \times 31,0$

2. Действие СРВ на рост рассады. Десятидневные проростки пикировались в ящики с вемлей по 75 проростков, которые через 20 дней в фазе крестика опрыскивались $0,01 \%$-ными растворами СРВ по $150 \mathrm{M} \Omega$ на ящик.

Через неделю после обработки было замечено, что в опытных вариантах рассада развивается лучше, листочки крупнее. Измерялись длина и ширина большого листа на двенадцати растениях с каждого варианта. Данные измерений представлены в табл. 1. Полученные результаты подтверждают визуальные наблюдения. Дополнительная обработка растворами СРВ способствует лучшему развитию рассады.

Для выявления влияния повторных опрыскиваний растворами СРВ возрастающих концентраций на дальнеӥшее развитие растений, рассада мерез неделю после первого опрыскивания снова обрабатывалась растворами стимулятора в прежних объемах, но повышенной концентрации $-0,025 \%$.

Наблюдения проводились через неделю. При этом разница между опытными растениями и контролем сохранялась (рис. 1-3). Данные измерений ширины и длины большого листа на двенадцати растениях в каждом варианте после статистичәской обработки представлены в табл. 1. 
Из полученных данных следует, что повторное опрыскивание благоприятно действует на рост рассады. Угнетающее действие не было обнаружено и при третьем опрыскивании рассады растворами СРВ 0,05\%-ной концентрации.

\section{Изучение действия СРВ в полевых условиях}

1. Опыты с гибридом табака. Перед посадкой корневая система рассады опытных вариантов табака отмывалась от земли и замачивалась. на 5 ч в растворах СРВ-1 (КП-211), причем исследовались растворы двух концентраций: 0,01 и 0,05\%-ные; корни контрольных растений замачивались на тот же срок в воде.

Удобрения вносились непосредственно перед посадкой рассады в бороздки в виде водного раствора солей: сернокислого аммония - 141 2, суперфосфата - 189 г и азотнокислого калия - 63 г на один ряд.

30 мая 1969 г. была проведена посадка, а через две недели - первые фенологические наблюдения. Результат оказался неожиданным - опытные растения выглядели меньше контрольных. Такая разница сохранялась в течение последующих наблюдений, проводившихся периодически через две недели. Вероятно, использованные концентрации стимулятора были слишком велики.

Дальнейшая обработка растений проводилась по методике, использованной М. Чайлахяном [3]. Часть опытных растений (100 штук -2 ряда) через месяц после высадки опрыскивалась раствором СРВ $0,01 \%$-ной концентрации из расчета $20 \Omega$ раствора на 100 растений. Два последующих ряда и контроль опрыскивались водой.

Наблюдения проводились через две недели после опрыскивания. Для получения объективных показателей из каждого варианта выкапывалось по пяти растений. Измерения отдельных частей растения проводились по методике, описанной Р. Турецкой [ $\left.{ }^{4}\right]$. Средние (из пяти) величины состветствующих измерений после обработки методом дисперсионного анализа представлены в табл. 2 и выражены в процентах к соответствующему контролю. Из данных табл. 2 видно, что через 1,5 месяца после высадки в грунт опытные и контрольные растения отличались по весу листьев. Хотя количество листьев опытных растений меньше, чем контрольных, вес их был выше. Листья опытных растений по внешнему виду были значительно крупнее контрольных.

Данные измерений растений, выращенных на неудобренном фоне, приведены в той же таблице. Из этих данных следует, что ни замачивание корневой системы, ни дополнительная обработка опытных растений опрыскиванием не оказали положительного действия при $0,01 \%$-ной концентрации.

Сочетание замачивания корневой системы в 0,05\%-ном растворе $\mathrm{CPB}$ с опрыскиванием при развитии растений на неудобренном фоне сказалось положительно. Вес листьев опытных растений значительно (на 26\%) превышал вес контрольных. Только обработка корневой системы растворами СРВ тормозит развитие стебля (сырой вес стебля до. $45 \%$ ниже контроля). Дополнительная обработка опрыскиванием способствует усиленному накоплению массы (табл. 2).

Хорошо заметно биологическое действие СРВ на корневую систему табака, что подтверждают данные табл. 2. При сравнении этих данных видно, что на удобренном фоне действие СРВ более эффективно, чем на неудобренном. На неудобренном фоне разница прироста существенна только в варианте, где корневая система замачивалась в 0,05\%-ном растворе СРB. 


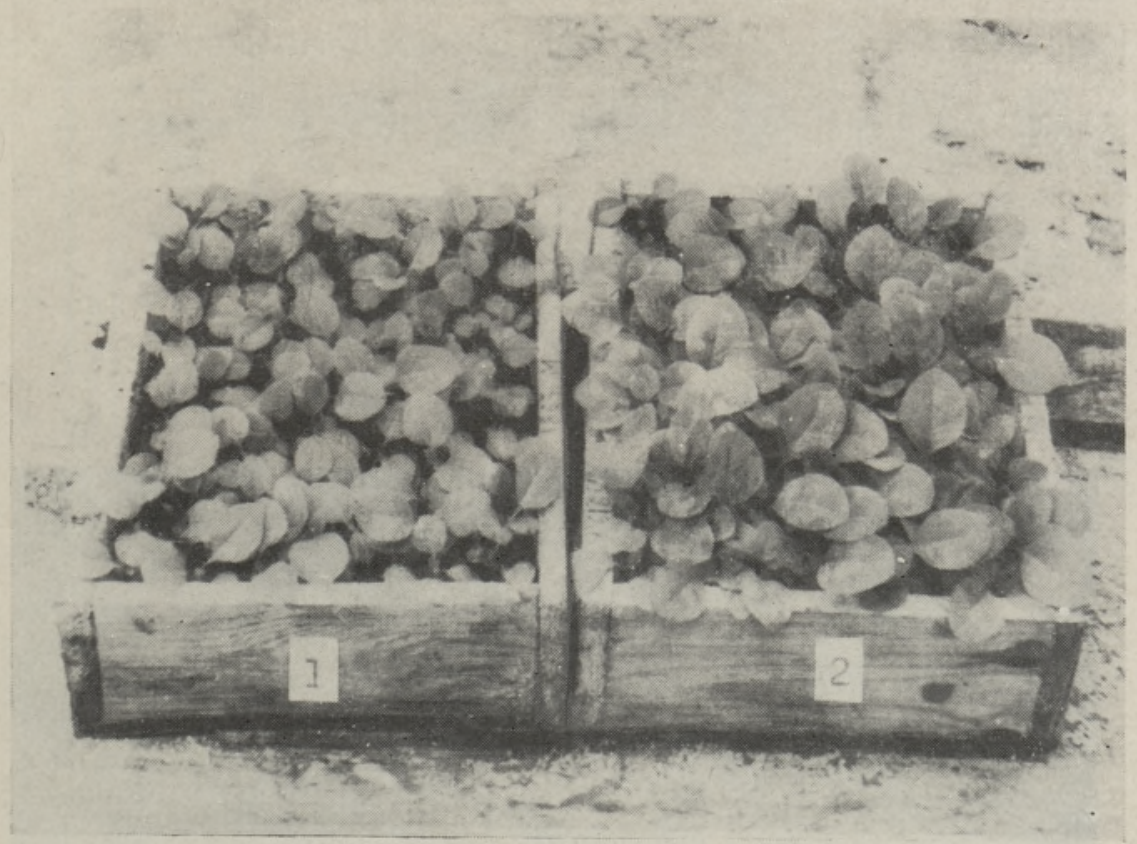

Рис. 1. Влияние СРВ-1 на рост рассады табака сорта 'Трапезонд 1867'.

1 - контроль (вода); 2 - рассада, получившая дополнительные опрыскивания растворами СРВ-1.

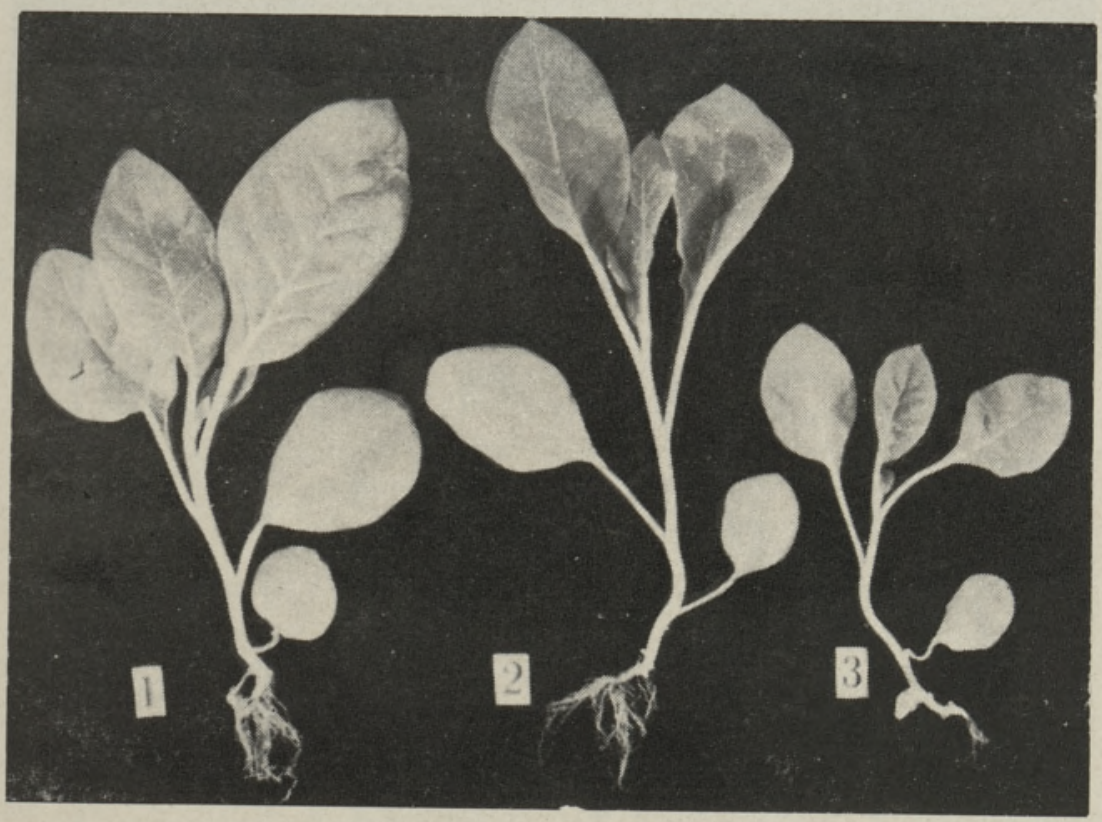

Рис. 2. Влияние разных солей ПФК на рост рассады табака сорта 'Трапезонд 1867'

1.- калиевая: 2 - кальциевая; 3 - контроль (вода), 


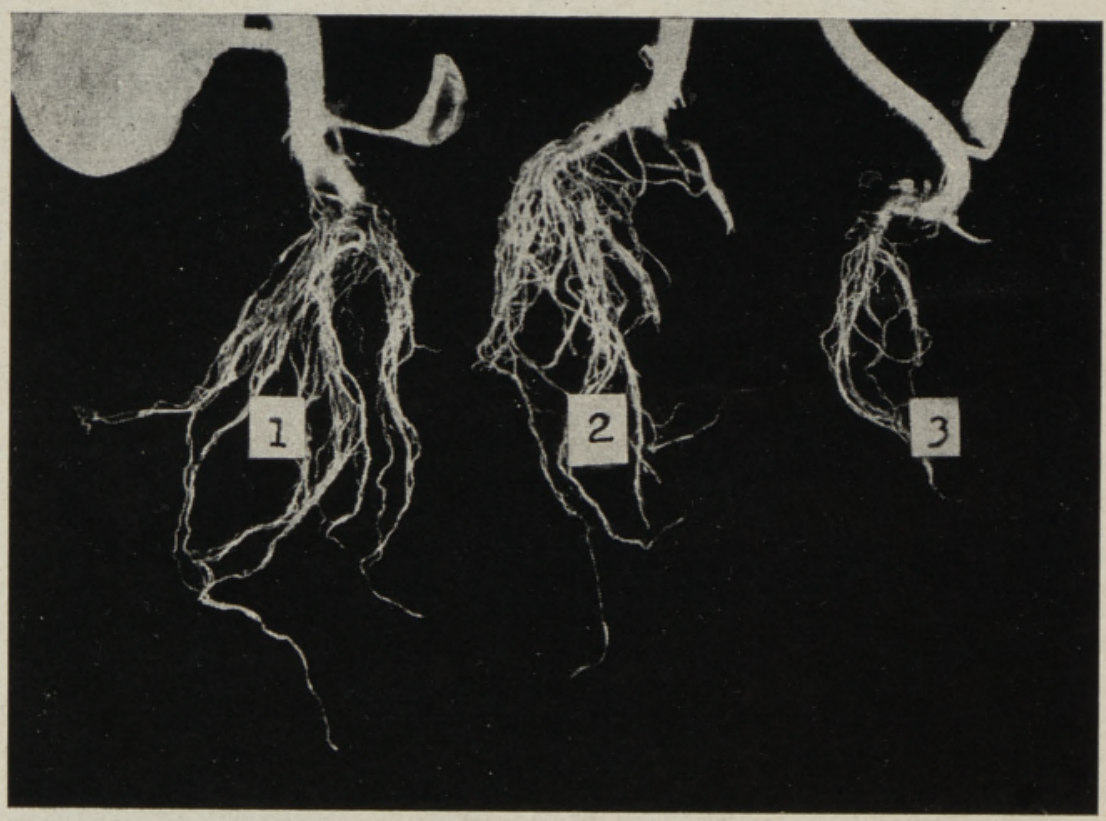

Рис. 3. Влияние разных солей ПФК на развитие корневой системы рассады табака сорта 'Трапезонд 1867'.

1 - калиевая; 2 - кальциевая; 3 - контроль (вода). 


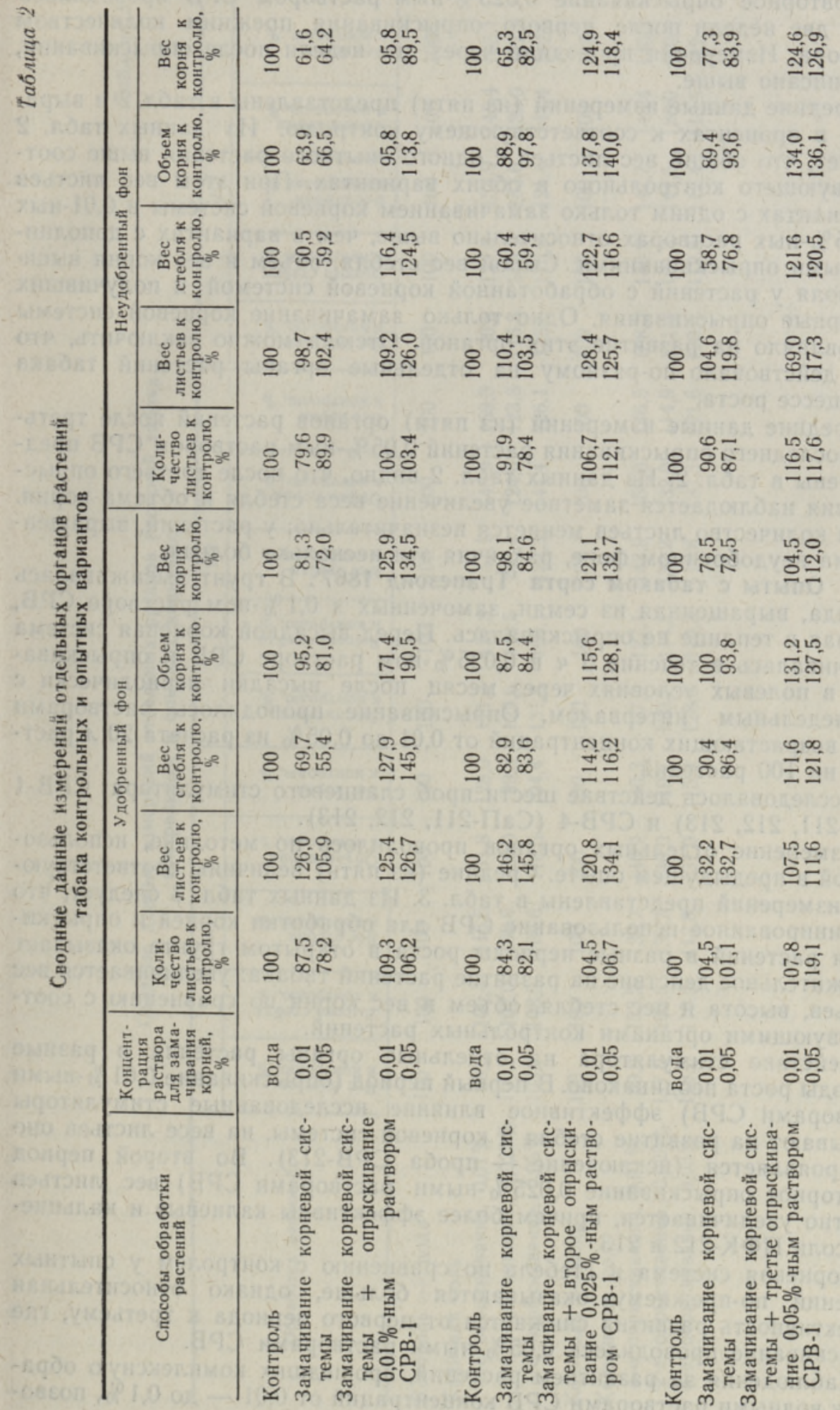


Повторное опрыскивание 0,025\%-ным раствором СРВ проводилось через две недели пссле первого опрыскивания прежним количеством раствора. Измерения проводили через две недели после опрыскивания, как описано выше.

Средние данные измерений (из пяти) представлены в табл. 2 и выражены в процентах к соответствующему контролю. Из данных табл. 2 следует, что общий вес листьев с одного опытного растения выше соответствующего контрольного в обоих вариантах. При этом вес листьевв вариантах с одним только замачиванием корневой системы в 0,01-ных и $0,05 \%$-ных растворах относительно выше, чем в вариантах с дополнительными опрыскиваниями. Сырой вес стебля, объем и вес корня выше контроля у растений с обработанной корневой системой и получивших повторные опрыскивания. Одно только замачивание корневой системы не повлияло на развитие этих органов. Отсюда можно заключить, что СРВ действовало по-разному на отдельные органы растений табака в процессе роста.

Средние данные измерений (из пяти) органов растений после третьего, последнего опрыскивания растений $0,05 \%$-ным раствором СРВ представлены в табл. 2. Из данных табл. 2 видно, что после третьего опрыскивания наблюдается заметное увеличение веса стебля и объема корня. Вес и количество листьев меняется незначительно; у растений, выращенных на неудобренном фоне, различия эти несколько больше.

2. Опыты с табаком сорта 'Трапезонд 1867'. В грунт высаживалась рассада, выращенная из семян, замоченных в 0,1\%-ном растворе СРВ, которая в теплице не опрыскивалась. Перед высадкой корневая система замачивалась в течение 5 в $0,025 \%$-ном растворе СРВ и опрыскивалась в полевых условиях через месяц после высадки периодически с двухнедельным интервалом. Опрыскивание проводилось растворами СРВ возрастающих концентраций от 0,01 до $0,05 \%$ из расчета $20 \Omega$ раствора на 100 растений.

Исследовалось действие шести проб сланцевого стимулятора: СРВ-1 (КП-211, 212, 213) и СРВ-4 (СаП-211, 212, 213).

Измерение отдельных органов проводилось по методике, использованной в предыдущем опыте. Средние (из пяти) величины соответствующих измерений представлены в табл. 3. Из данных табл. 3 следует, чтс комбинированное использование СРВ для обработки корней и опрыскивания растений в разные периоды роста в открытом грунте оказывает положительное действие на развитие растений табака: увеличивается вес листьев, высота и вес стебля, объем и вес корня по сравнению с соответствующими органами контрольных растений.

Действие стимулятора на отдельные органы растения в разные периоды роста неодинаково. В первый период (опрыскивание $0,01 \%$-ными растворами СРВ) эффективное влияние исследованные стимуляторы оказывают на развитие стебля и корневой системы, на весе листьев оно не проявляется (исключение - проба СРВ-213). Во второй период (повторное опрыскивание 0,025\%-ными растворами СРВ) вес листьев. заметно увеличивается, причем более эффективны калиевые и кальциевые соли ПФК-212 и 213.

Корневая система и стебель по сравнению с контролем у опытных растений по-прежнему оказываются больше, однако относительная эффективность развития снижается от первого периода к третьему, где опрыскивание проводилось $0,05 \%$-ными растворами СРВ.

Наблюдения за развитием растений, прошедших комплексную обработку водными растворами СРВ концентраций от $0,01-$ до $0,1 \%$, позволяют сделать следующие выводы: 
0
0
0
0
0
0
0

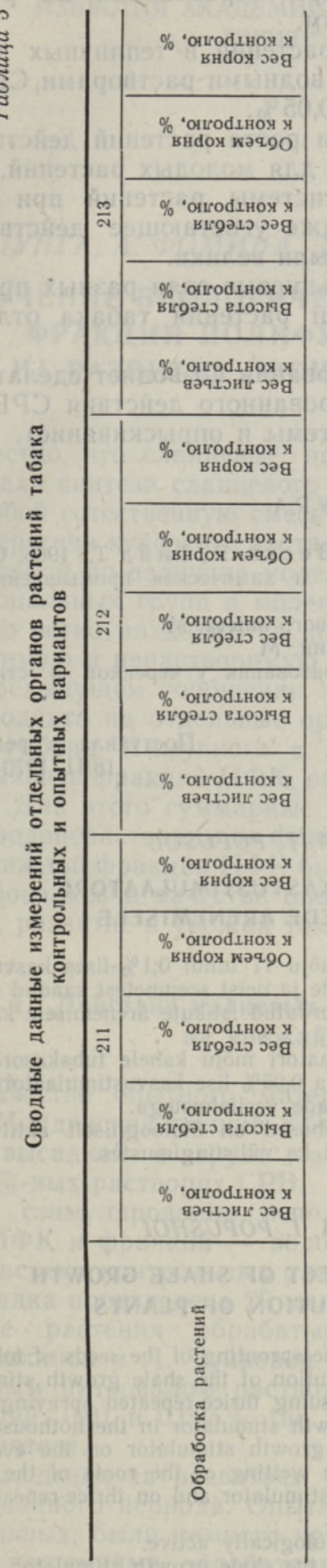

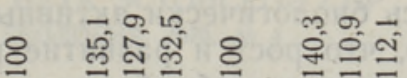

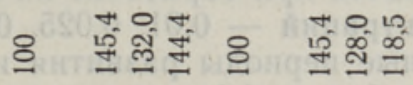

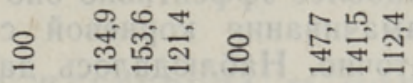

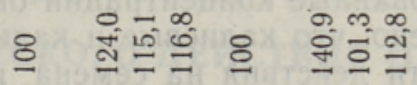

\&

\& 욤ำ \&

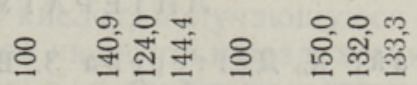

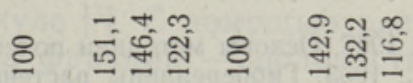

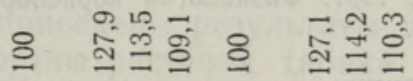

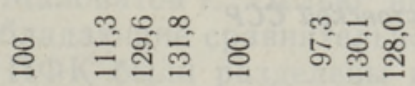

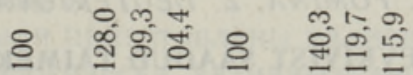

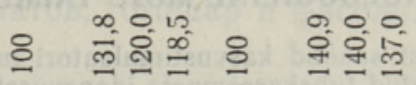

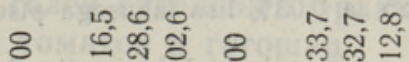

=

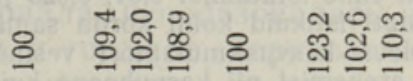

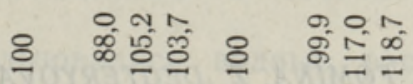

ํํำ 둥영 :

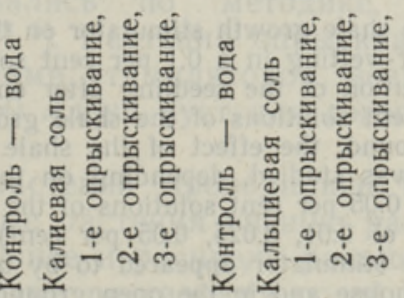


1. Сланцевое ростовое вещество при опробовании на растениях табака оказалось биологически активным.

2. Выявлено, что рост и развитие растений в тепличных условиях заметно усиливаются при обработке их водными растворами СРВ опробованных концентраций - 0,01, 0,025, 0,05\%.

3. В различные периоды развития и роста растений действне СРВ неодинаково. Наиболее эффективно оно для молодых растений.

4. Одного замачивания корневой системы растений при высадке в грунт недостаточно. Наблюдалось даже угнетающее действие, возможно, использованные концентрации были велики.

5. Установлено, что калиевые и кальциевые соли разных проб ПФК по эффективности действия на семена и растения табака отличаются друг от друга незначительно.

6. Использованная методика исследования позволяет сделать вывод лишь о конечных результатах комбинированного действия СРВ (замачивание семян, обработка корневой системы и опрыскивание).

\title{
ЛИТЕРАТ У РА
}

1. Фомин а А., Р айг Х., Д егте ре в а 3., В ески Р., Т ийд Т., 1966. Сланцевый стимулятор роста растений. Сланцевая и химическая промышленность (1): $14-17$.

2. Д осп ехо в Б., 1967. Основы методики полевого опыта. М.

3. Ч а й л а х ян М., 1963. Гиббереллины растеннй. $M$.

4. Т урецк ая Р., 1961. Физиология корнеобразования у черенков и стимуляторы роста. $M$.

\author{
Ннститут химии \\ Академии наук Эстонской ССР
}

Поступила в редакцию $18 /$ II 1970

\section{VEERA PUNGA, A. FOMINA, Z. DEGTERJOVA, I. POPUSOI}

\section{POLLEVKIVIST SAADUD TAIMEKASVUSTIMULAATORI BIOLOOGILINE MOJU TAIMEDE ARENEMISELE}

Uuriti pōlevkivist saadud kasvustimulaatori mōju 17 tundi $0,1 \%$-lises kasvustimulaatori vesilahuses leotatud tubakaseemnete idanevusele ja neist seemnetest saadud ning kolm korda sama $0,01,0,025$ ja $0,05 \%$-lise lahusega piserdatud istikute arenemisele kasvuhoone tingimustes.

Välistingimustes uuriti põlevkivi kasvustimulaatori mõju kahele tubakasordile, mille istikute juuri niisutati enne istutamist $0,01,0,025$ ja $0,05 \%$-lise kasvustimulaatori vesilahusega ja hiljem piserdati istikuid kolm korda samade vesilahustega.

Leiti, et kônesoleva kasvustimulaatori vesilahused on bioloogiliselt aktiivsed ning kiirendavad taimede arenemist nii kasvuhoone kui ka välistingimustes.

\section{VEERA PUNGA, A. FOMINA, Z. DEGTERYOVA, I. POPUSHOI}

\section{STUDY OF THE BIOLOGICAL EFFECT OF SHALE GROWTH STIMULATOR ON THE EVOLUTION OF PLANTS}

The effect of the shale growth stimulator on the sprouting of the seeds of tobacco was studied after 17-hour-wetting in a 0.1 per cent solution of the shale growth stimulator as well as on the evolution of the seedling after ensuing thrice-repeated spraying with 0.1 , 0.025 and 0.05 per cent solutions of the shale growth stimulator in the hothouse.

In the open ground, the effect of the shale growth stimulator on the evolution of 2 sorts of tobacco was studied, depending on the wetting of the roots of the seedlings with $0.01,0.025$ and 0.05 per cent solutions of the stimulator and on thrice-repeated spraying (with solutions of $0.01,0.025,0.05$ per cent).

Solutions of the stimulator appeared to by biologically active.

Both in the hothouse and in the open ground the shale growth stimulator intensifies the evolution of plants. 